\title{
Learning about Conflict and Negotiations through Computer Simulations: The Case of PeaceMaker $^{1}$
}

\author{
Esra Cuhadar \\ Bilkent University \\ AND \\ Ronit KAMPF \\ Tel Aviv University
}

\begin{abstract}
This paper is based on a cross-national experimental study conducted among American, Turkish, Israeli-Jewish, and Israeli-Palestinian students using a computer game called "PeaceMaker." The game is a highly realistic and complex simulation of the Israeli-Palestinian conflict. PeaceMaker was used for educational and experimental purposes in a classroom setting and each student played the game in both Israeli and Palestinian decision maker roles. Our purpose was to evaluate the game's effectiveness as a pedagogical tool in teaching about conflict and its resolution, especially with regard to generating knowledge acquisition, perspective taking as a crucial skill in conflict resolution, and attitude change. We were also interested in understanding whether these effects changed depending on whether the participants were direct parties to the conflict or not. In order to gauge the effect of the game in these areas, we used a pre- and post-intervention experimental design and utilized questionnaires. We found that the game increased the level of knowledge about the conflict for the Israeli-Jewish, Israeli-Palestinian, American, and Turkish students. We also found that the game successfully contributed to perspective taking among Turkish and American students only on a contemporary issue related to the conflict.
\end{abstract}

Keywords: conflict and negotiation teaching, computer-based simulations, active learning and teaching, Israeli-Palestinian conflict

As a method of "active learning and teaching," simulations have become one of the most widely used pedagogical tools in the teaching of conflict analysis and resolution. Role plays and simulations are also used in the teaching of international relations and crisis decision making (for example, Hermann 1969; Lantis 1998; Boin, Kofman-Bos, and Overdijk 2004; Asal 2005; Lay and Smarick 2006; Gehlbach, Brown, Ioannou, Boyer, Hudson, Niv-solomon, Maneggia, and Janik 2008), but it is the skills training aspect (for example, negotiation and mediation

\footnotetext{
${ }^{1}$ Authors' note: The authors would like to thank Ruveyda Celenk for her contributions to the study during the collection of data.

${ }^{2}$ Active teaching and learning is defined as a pedagogical approach that aims at replacing the traditional lecture-discussion-based instruction with a more student-centered approach. It aims at teaching critical thinking skills and the construction of knowledge where students are encouraged to take part in an experiential learning environment (Krain 2010).
} 
skills) of the conflict resolution field that motivates instructors to rely heavily on simulations and role plays as a teaching method (Brown, Boyer, Mayall, Johnson, Meng, Butler, Weir, Florea, Hernandez, and Reis 2003; Wilkenfeld, Young, Queen, and Assal 2005; Druckman and Ebner 2008; Movius 2008:515).

Simulations in conflict resolution can take different forms, but as Alexander and LeBaron put it, the bottom line is "a learning activity in which participants are asked to assume a role, the characteristics of which are usually provided to them in written form, and to play out a negotiation or part of a negotiation with others who also have assumed roles" (2009: 182).

Despite its extensive use, the effectiveness and cultural relevance of simulations have only recently been assessed in a systematic manner in international relations (Powner and Allendoerfer 2008; Baylouny 2009; Krain 2010; Lantis, Kille, and Krain 2010; Raymond 2010; Asal and Kratoville 2013) and conflict resolution (Movius 2008). Most of the evidence, until recently, regarding the effectiveness of simulations remained anecdotal, focusing on scholars' individual experiences in a classroom setting (Asal and Kratoville 2013:136) or based on student-reported gains often without the inclusion of a pretest or a control group. Several studies conducted recently tried to fill this void by introducing systematic measurement using pretest and post-test questionnaires (Krain and Lantis 2006) or introducing a control group (Lay and Smarick 2006; Powner and Allendoerfer 2008). However, these studies present mixed results about the effectiveness of simulations. Some (for example, Krain and Lantis 2006; Powner and Allendoerfer 2008:76) argue that active learning in general increases student performance and simulations are not necessarily better than other active learning methods. Others suggest that simulations specifically are more effective in knowledge acquisition than traditional lecture-based methods (Krain and Shadle 2006; Lay and Smarick 2006).

Apart from a few studies systematically focusing on the effectiveness of simulations, research is even more sparse on the effects of simulations in cross-cultural settings and the implications of using web-based and digital technologies in simulations. ${ }^{3}$ Existing studies are very valuable and mostly focused on the effectiveness of decision support system technologies in negotiation simulations such as ICONS, the computer assisted International Communications and Negotiations Simulation (Torney-Purta 1998; Wilkenfeld et al. 2005), or E-Nego-Motion (Druckman, Dannenman, Filzmoser, Gettinger, Koeszegi, Mitterhofer, Reiser, Schoop, Vetschera and van der Wijst 2011). Yet, among these studies, very few focused on the effectiveness of digital "games" that are designed to teach about a particular conflict and negotiation process where students interact with a computer via a game and negotiate the conflict. This study addresses the following areas within the domain of active learning and teaching: exploring the effectiveness of simulations in a cross-cultural setting and of computer-based conflict and negotiation simulations where students interact with and negotiate with the help of a computer game. We report the findings from a systematic cross-cultural study that focused on the effectiveness of "PeaceMaker," a complex and realistic computer simulation of the Israeli-Palestinian conflict and negotiations. PeaceMaker was developed by ImpactGames with support from the United States Institute of Peace.

Using PeaceMaker, we conducted a cross-national experimental study among American, Turkish, Israeli-Jewish, and Israeli-Palestinian university students. The game was used for educational purposes in a classroom setting. Each student played the game in both Israeli and Palestinian decision maker roles. Our pur-

\footnotetext{
${ }^{3}$ An exception to this is a recent study group brought together in the International Studies Association to crossnationally examine various active learning and teaching methods including some computer-based active learning tools. The workshop was held in ISA 2012 and resulted in an ISA panel in 2013 where preliminary research results concerning the use of active teaching and learning methods in classrooms from different parts of the world were presented. See ISA 2013 panel titled Think Globally, Teach Locally? Active Teaching and Learning in CrossNational Perspective.
} 
pose was to understand how effective the game was as a pedagogical tool in teaching conflict resolution especially with regard to learning new knowledge about the conflict, perspective taking - a crucial skill in conflict resolution-and attitude change. Simulation is considered a preferable method in generating new insight, empathy, and perspective taking (Williams 2006; Baylouny 2009:215). We were also interested in understanding whether these effects changed with the context and when the participants were direct parties to the conflict or not.

We measure the following outcomes: (i) whether playing the game contributes to the level of knowledge of the students about the conflict and about the other party; (ii) whether playing the game contributes to the development of perspective taking, which is a crucial negotiation skill; (iii) whether the game changes the attitudes of the students about the conflict; and (iv) are there any differences in terms of knowledge acquisition and perspective taking between participants who are direct parties to the conflict and those who are secondary/third parties?

\section{Use of Simulations in Teaching Conflict and Negotiation}

The effectiveness of simulations in conflict resolution has been scrutinized in systematic research (Torney-Purta 1998; Loewenstein and Thompson 2000; Brown et al. 2003; Druckman and Ebner 2008; Baylouny 2009). Particularly in the context of negotiations, several projects have marked significant progress. The ICONS project at the University of Maryland started using simulations since 1980s and was also used to assess the effectiveness of several simulation methodologies (Torney-Purta 1998; Wilkenfeld et al. 2005). ICONS involved humanbased simulation of crisis negotiations where participants were assigned role plays as representatives of a country with the help of a computer-based decision support system. The decision support system was used to improve the performance of negotiators. Research based on ICONS found that learning via the ICONS simulation was more effective than learning with traditional methods (Torney-Purta 1998). Later, the ICONS project developed into another webbased simulation program called GlobalEd and has been extended to high school and middle school students (Brown et al. 2003; Gehlbach et al. 2008). Several studies with GlobalEd too showed that it was effective in teaching students problem-solving and negotiation skills (Brown et al. 2003; Gehlbach et al. 2008).

At the same time, simulation as a teaching method has become subject to skepticism (Lewicki 2000; Movius 2008). Scholars voiced the need to reassess common sense assumptions about negotiation teaching especially with regard to the benefits of role plays and simulations. Criticisms concentrated on the following issues: First, role playing in simulations elicits cultural stereotypes (Kersten, Koszegi and Vetschera 2003). Second, simulations put students in a synthetic situation, which has no relevance to real life and misses the complexity of reality (Volkema 2007; Honeyman, Coben, and De Palo 2010). Role plays isolate students from a meaningful context they can genuinely relate to (Alexander and LeBaron 2009). Finally, role plays and simulations are criticized for having little or no transference of skills to real-life settings (for example, Loewenstein and Thompson 2000:405-406; Nadler, Thompson, and Van Boven 2003; Movius 2008; Alexander and LeBaron 2009).

Following these criticisms, some voiced the need for more research to understand what conditions influence the effectiveness of simulations (Druckman and Robinson 1998; Movius 2008). ICONS and GlobalEd studies suggest that simulations are more effective compared with traditional lecture and discussions because they are successful in raising the motivation of students. Druckman and 
Ebner (2008:467) showed that role plays motivate learning of negotiation skills when students are passive, but otherwise they are not necessarily more effective than learning through lectures and case studies. In fact, they argue that simulations may activate learning better for simulation designers than for participants. They advocate a pedagogical approach in which students are taught concepts first and then are encouraged to design their own negotiation simulations.

Other critiques went further and suggested supplementing, if not replacing, simulation with other methods that better incorporate real-life settings (Ebner and Efron 2005; Volkema 2007; Alexander and LeBaron 2009). "Real-life" stakes were introduced in conflict resolution teaching in varying degrees. For example, while Ebner and Efron (2005) still used role plays and simulations, they based the scenarios they use on current affairs from real-life. Volkema (2007) and several others on the other hand, introduced monetary consequences into the role plays by asking participants to put in money. Some others advocated "adventure learning," referring to placing participants in real-life negotiation situations outside of the classroom. The project initiated by the Hamline University Dispute Resolution Institute called for an assessment of negotiation pedagogy and explored new training methods for negotiation teaching, one of which was incorporating "adventure learning" into the teaching of conflict resolution (Honeyman et al. 2010).

Research discussed above addressed some of the criticisms about the use of role plays and simulations. There is less research, however, on the effectiveness of simulations on attitude change, transfer of skills from one setting to another, and perspective taking. Two studies are valuable in this regard. Gehlbach et al. (2008:909) argued that GlobalEd simulation among social studies students increased students' propensity to engage in social perspective taking. Baylouny (2009) also argued that nongame simulations conducted in order to teach about Middle East conflicts at the Naval Postgraduate School helped create new insights about the region and changed the perspectives of the participants toward a less ethnocentric direction.

There are still several holes in the literature on evaluating simulations at the moment. First, the role of culture in effective learning via simulations is still untapped. There is need for systematic assessment in cross-cultural settings. Most evaluation studies are undertaken within one country, even though different schools are sometimes selected in that country. Recently, several studies emerged exploring the gender differences in learning (for example, Brown et al. 2003), but cultural differences in learning from simulations is still absent. In this study, our purpose is to address the cross-cultural dimension of active learning using conflict and negotiation simulations. Second, most of the studies of simulations focused on traditional simulations based on role playing and negotiating with another human being. Evaluating computer-based simulations using digital "games" is not explored so far. Our second purpose is to evaluate the effectiveness of a computer-based simulation of the Israeli-Palestinian conflict and negotiations. Third, most of the systematic assessment literature focused on knowledge acquisition for measurement. In this study, in addition to the measurement of knowledge about the conflict, we also measure the change in perspective taking and attitude change, which are critical conflict resolution skills.

\section{Simulations Incorporating Technology: Approximating Complexity and Reality}

Technology is incorporated into conflict resolution training inside and outside the classroom setting. Online conflict resolution courses are now offered in a variety of academic institutions (Ebner 2008; Bhappu, Ebner, Kaufman, and Welsh 2009; Matz and Ebner 2010). E-negotiation and e-mediation systems are made available in order to help negotiators satisfy their requirements and to 
assist them in negotiations (Druckman, Druckman, and Arai 2004; Druckman et al. 2011; Lin, Gev, and Kraus 2011). Some of them compared the effectiveness of automated mediators with the absence of mediators in negotiations such as AniMed (Lin et al. 2011). Others, such as the GlobalEd Project (Brown et al. 2003) assessed the effectiveness of negotiation simulations using Internet-based interface. Technology has become prevalent in the use of decision support systems in negotiation simulations (Wilkenfeld et al. 2005) and web-based simulation programs like GlobalEd (Brown et al. 2003; Gehlbach et al. 2008).

Technology certainly provides new opportunities for active learning and teaching such as cost cutting and bringing people together when otherwise not possible. More importantly, technology can be used to artifically create more complex and structured simulation settings in a classroom environment which can help overcome the artificiality, randomness, and out-of-context characteristics of traditional role plays and simulations. In traditional role plays, students may tend to adhere less to their written instructions and thus, the effectiveness of role play is often left to their motivation, understanding, and improvisation. Technology, on the contrary, can be used to put students into more structured role plays simulating complex and realistic settings. Wilkenfeld et al., for instance, note the benefits of decision-support systems in the University of Maryland negotiations as follows: they help privately organize information, develop prenegotition strategies, evaluate and propose mid-negotiation offers, generate prescriptions, and, most importantly, aid negotiators in overcoming their cognitive limitations (2005:28). This system also proved very valuable in ensuring that every participant shares a common understanding of the relative value of different actions and different possible outcomes in the negotiation context (Wilkenfeld et al. 2005:28).

A significant advantage of technology, and specifically a simulation like PeaceMaker, or a decision support program like that of Wilkenfeld's is that they capture real-life complexity while structuring decision making in a controlled environment. As Wilkenfeld et al. (2005) suggest, such tools are also valuable for designing experiments based on simulations. Technology may be a way to overcome the artificiality and randomness of traditional simulations and role plays. By introducing higher complexity to the simulation of a real-life situation in a more structured way, technology can make learning experience less dependent on student acting skills.

Despite its benefits, evidence on the effectiveness of the use of technology in negotiation simulations is scarce. Research on web-based and digital technologies in teaching and learning (for example, Hannafin and Kim 2003; Lawless and Brown 2003) focuses on innovations in using the world wide web. Few studies (Lin et al. 2011; Chalamish and Kraus 2012) systematically analyzed the effects of technology support as opposed to no technology support in negotiation simulations.

Use of technology introduces new challenges to human interaction and communication in conflict resolution. Some argue that face-to-face negotiation has many advantages over e-negotiation, others think the opposite (Galin, Gross, and Gosalker 2007). In an experimental study comparing an e-mediator with live mediation, Druckman et al. (2004) found both advantages and disadvantages associated with the e-mediator. E-mediation produced more agreements than live mediation, but negotiators still preferred live mediation (Druckman et al. 2004:504). Similarly, Lin et al. (2011) found positive outcomes for the use of AniMed, the automated animated mediator, compared with situations where there was no mediator help to negotiating parties.

In this respect, PeaceMaker is a unique teaching tool that allows some of these unexplored issues related to the use of technology in conflict resolution teaching to be studied systematically. It combines the advantages of role play 
and simulation with more structured interaction and allows for systematically tracking and assessing student actions in a conflict and negotiation setting.

PeaceMaker has been used in research only once in order to assess its efficacy as a teaching tool with American students (Gonzalez, Saner, and Eisenberg 2012). Our study is different and goes beyond the previous study. First of all, we assess the effectiveness of this computer-based simulation in terms of both knowledge acquisition (learning about the conflict), attitude change (attitude toward the conflict issues), and perspective taking. We also add a cross-cultural assessment to the game by having students from different cultural and political backgrounds. We conducted the study with Israeli, Palestinian, American, and Turkish students. Furthermore, we assess the effectiveness of the game by distinguishing between the direct parties and the non-parties to the conflict. We expect that the simulation will have different effects on these respective groups.

\section{The PeaceMaker Game}

PeaceMaker has several advantages as a teaching tool compared with a text-based simulation and role play. It is not only based on a real-life conflict, but is also one of the most complex simulations of this conflict formulated so far for teaching purposes. In this sense, it is still role-playing, but the students are within a structured game and are not isolated from a realistic context.

PeaceMaker is inspired by historical real-world events. A player can assume the role of either the Israeli Prime Minister or the Palestinian President and engage in a series of decisions with the aim of satisfying constituents on both sides of the conflict. Impact Games developed this game with the help of advisors in Israel, Palestine, and the United States (Burak, Keylor, and Sweeney 2005). The game was also supported by the United States Institute of Peace as an educational tool.

The game aims at a two-state solution to the Israeli-Palestinian conflict by satisfying constituents on both sides. In fact, this is not the only solution offered for the conflict, but it is the consensus solution accepted by the main parties and was the aim of past peace talks, UN resolutions, and the US-backed "road map." A two-state solution can be reached in PeaceMaker by taking different actions rather than focusing on particular ones (Burak et al. 2005). In order to resolve the conflict in the game, players are required to make trade-offs between a variety of actions. Finally, participants in the current study hold different views regarding a two-state solution. In fact, support for a two-state solution did not explain resolving the conflict in the game for both Israeli and Palestinian roles. Participants opposing a two-state solution resolved the conflict in the game no less than those supporting it.

PeaceMaker can be played in English, Hebrew, and Arabic, on calm, tense, or violent conflict levels, differing in the frequency of events that appear on the screen and are beyond the player's control (see Figure 1 for a screenshot of PeaceMaker). In order to deal with these events, a player can select actions in one of the three main categories: security, political, and construction, each branching into a variety of sub-categories. The player can draw upon information on relevant events appearing on the screen in text, videos, and pictures from real-time news broadcasts and by clicking on maps, cities, and polls, enabling her to formulate an informed game strategy.

Players accumulate points for both sides according to the actions taken in the game. The scores, calculated by a function within the game, are related to the polls registering the level of satisfaction of different nations, of political groups within the country and around the world in response to the leader's actions. In order to resolve the conflict in the game, scores for both Israeli and Palestinian sides must reach 100 points each. If either score drops below -50 , the player 


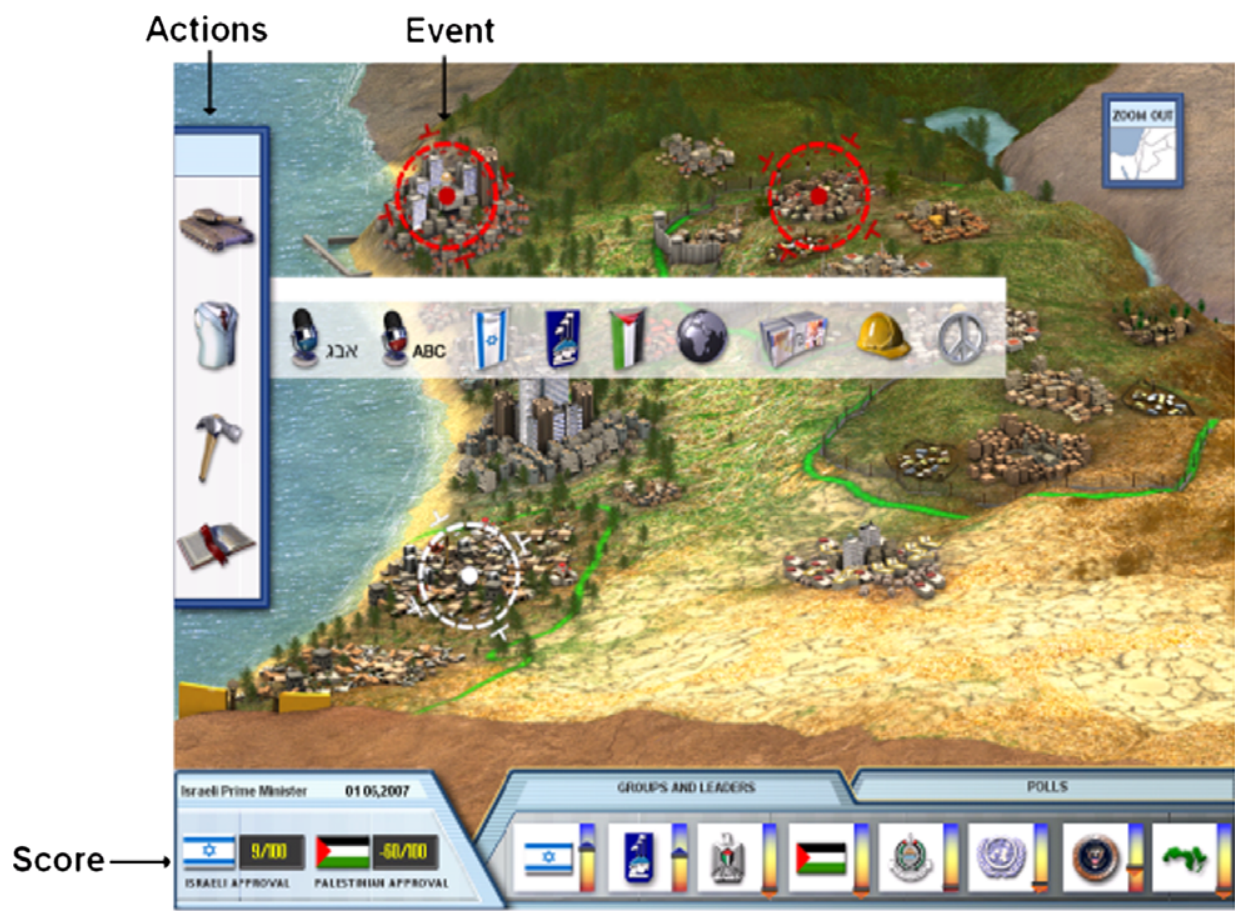

Fig 1. Screenshot of PeaceMaker ${ }^{4}$

loses the game. Changes in the scores were determined by the developers based on a series of tests with international experts.

\begin{abstract}
Method
Using simulations for experiments is an established tradition in the study of negotiation and mediation processes (Wilkenfeld et al. 2005; Druckman 2011). We designed the current simulation experiment to assess game effects on knowledge acquisition about the conflict and on perspective taking regarding key issues in the conflict. Does the game affect participants' acquisition of knowledge about the conflict? Does the game change the attitude of the participants toward the "other" and the conflict? Does it contribute to perspective taking regarding the conflict? Perspective taking is one of the most important outcomes in conflict resolution as a pre-requisite for developing empathy. Are there any differences in terms of resolving the conflict, knowledge acquisition, and perspective taking between those who are direct parties to the conflict (in this research, Israelis of Jewish origin and Israelis of Palestinian origin) and those who are third parties (Americans and Turks)? Resolving the conflict in the game requires participants to satisfy constituents on both sides of the conflict and effectively negotiate a solution to the Middle Eastern situation. Therefore, whether the four groups differ in resolving the conflict in the game and what explains successful resolution of the conflict in the game is an important one. We also examined whether the four groups differed in the action type taken in the game (Security, Political, and Construction) focusing on any difference in actions taken by participants that are direct parties to the conflict. Action type
\end{abstract}

\footnotetext{
${ }^{4}$ The screen shot shows the toolbar from which a player selects actions in response to events that appear on the map of Israel, the West Bank, and the Gaza Strip, and the scores for the Palestinian and Israeli sides.
} 
can indicate predispositions to specific actions. We examined the above-mentioned questions in which participants played the PeaceMaker game in both roles: the Israeli Prime Minister role and the Palestinian President role, in random order.

\section{Participants}

One hundred and forty-seven undergraduate students ranging from sophomores to seniors participated in the study: 38 Turkish students were from Bilkent University, 50 Israeli students of Jewish origin were from Tel Aviv University, 39 American students were from the School for Overseas Students at Tel Aviv University, and 20 Israeli students of Palestinian origin were also from Tel Aviv University.

The four groups did not differ in terms of gender $\left(X^{2}(146,3)=.40, p<.94\right)$. Turkish participants were $55 \%$ women and $45 \%$ men. American participants were $51 \%$ women and $49 \%$ men. Israeli participants of Jewish origin were $55 \%$ women and $45 \%$ men. Israeli participants of Palestinian origin were $55 \%$ women and $45 \%$ men. The four groups differed in terms of age. Israeli students of Jewish origin were older $(M=25.12, S D=1.32)$ than American students $(M=22.7$, $S D=2.39)$, Turkish students $(M=21.42, S D=1.59)$, and Israeli students of Palestinian origin $(M=21.1, S D=1.17), F(3,146)=44.57, p<.0001$.

\section{Design and Procedure}

The study was conducted as part of classes in political science and conflict resolution. The data on Israeli students of Palestinian origin were collected in a guest lecture given by one of the authors as part of students' activities in Tel Aviv University.

The data on Turkish and Israeli students of Jewish origin were collected in winter 2010; the data on American students were collected in spring 2010; and the data on Israeli students of Palestinian origin were collected in fall 2010. No major event happened between the data collection with Turkish, Israeli, and American students. In May 2010, the Flotilla crisis happened between Turkey and Israel disrupting the relations between the two countries. However, this crisis is related to relations between Israel and Turkey, and Turkish and Israeli data were already collected before the crisis. The questionnaire included questions about the most recent event until then, the Gaza war, and hence, did not include any question concerning the Flotilla event. Due to the difficulties in accessing Palestinian students, the collection of the Palestinian data was delayed into a few months after the flotilla event. However, at that point, we decided to use the same questionnaire for Palestinian students as well and did not ask any questions regarding the Flotilla crisis. The fact that the Peacemaker game was about the Israeli-Palestinian conflict and the crisis concerned Turkey and Israel, we thought the Flotilla crisis would not have much affect on the Palestinian attitudes toward the two-state solution and the Israeli-Palestinian conflict.

The experiment took up to three and a half hours and included four parts. First, participants were introduced to the PeaceMaker game and played a short demo. Second, they filled in a short questionnaire consisting of a battery of knowledge questions on the Israeli-Palestinian conflict, political attitudes toward various aspects of the Israeli-Palestinian conflict, level of interest in the Israeli-Palestinian conflict, news sources on the conflict, average of weekly hours playing computer and video games, average of weekly hours spent online and demographics. Third, participants played the game twice, once in the role of the Israeli Prime Minister and once in the role of the Palestinian President, in random order. All participants played PeaceMaker in English at the calm conflict level (i.e., low frequency of inciting incidents). The participants were required to write 
down every action they took in the game, to facilitate analysis of the type of action (Security, Political, or Construction) participants took in the game. Finally, after playing the game, the participants again filled in a short questionnaire, examining knowledge on the Israeli-Palestinian situation, perspective taking on various aspects of the Israeli-Palestinian conflict, and reflections on their experience with PeaceMaker. The questionnaire used before and after the game was almost identical in content with the exception of a few additional questions in the post-game questionnaire deliberating their experience with the game.

\section{Measures}

A questionnaire was used to gather information on the background knowledge, perspective taking on various issues in the conflict, nationality, religious affiliation, and political attitudes of the participants.

As our measure of background knowledge, students were asked a battery of 24 open-ended and close-ended knowledge questions on various political and historical aspects of the conflict varying in degrees of difficulty, such as: name the parties to the 1993 Oslo agreement; who is Gilead Shalit; and what is the meaning of the Nakba Day. ${ }^{5}$ The coding differentiated between correct answers, don't know answers, and incorrect answers. We used these factual questions both in the pre- and post-game questionnaires in order to assess the knowledge level of the students about the conflict prior to and after the game.

Apart from the factual knowledge questions, we had two measures for assessing attitudes and perspective taking in the conflict. The first measure asked how right each side is on the Gaza operation. The following scale was used in this question: 1. Palestinians are absolutely right, 2. Palestinians are somewhat right, 3. Both sides are equally right, 4. Israelis are somewhat right, and 5. Israelis are absolutely right. Other than the Gaza operation, this measure also examined "how right is each side" on key issues in the conflict including water, refugees, borders, settlements, Jerusalem, and security. The abovementioned scale from 1 to 5 was used for this measure as well. For the purpose of data analysis, the average of answers given on the six key issues was used as a measure of perspective taking in the conflict. We assessed the attitudes of students on the Gaza operation separately, because the former was a recent event that received extensive media coverage and public debate at the time of the study, as opposed to the other long lasting historical issues.

Political attitudes were measured by the following question: If you were to place yourself on the following scale, where would you locate yourself in political terms? A ten-point scale was used in this question, 1 representing extreme left and 10 representing extreme right. For the purpose of data analysis, this scale was divided into three categories: left, center, and right.

Support for two-state solution was measured by the following question: How much do you support a two-state solution to the Israeli-Palestinian conflict? The following scale was used in this question: 1. Not at all, 2. Somewhat oppose, 3. No idea, 4. Somewhat support, and 5. Absolutely support. The category "no idea" was excluded from data analysis ( $15 \%$ of the participants selected this category), and the scale was divided into two categories: support or oppose.

The main dependent measure was whether participants were successful (1) or not $(0)$ in resolving the conflict in the game. Another dependent measure was the proportion of construction, political, and security actions a participant took in the game, separately for the Israeli role and for the Palestinian role. The number of each type of action a participant took was divided by the total

\footnotetext{
${ }^{5}$ The questionnaire used for the experiment can be provided upon request from the authors.
} 
number of actions she took, defining the variables Construction, Political, and Security.

\section{Statistical Procedures}

In order to examine game effects on knowledge acquisition, perspective taking, and attitude change, we used a Repeated Measures ANOVA. We investigated the effect of playing the game on the abovementioned measures at two separate time points: pre- and post-game intervention. The important point with this study design is that the same participants are measured twice on the same dependent variable. Therefore, this test detects any overall differences between related means.

\section{Results and Discussion}

\section{Resolving the Conflict in the Game}

Overall, $33 \%$ of the participants resolved the conflict in one role and $11 \%$ of the participants resolved the conflict in both roles. In the Israeli role, $8 \%$ of Turkish participants, $21 \%$ of American participants, $32 \%$ of Israeli participants of Jewish origin, and $40 \%$ of Israeli participants of Palestinian origin resolved it. In the Palestinian role, 30\% of Turkish participants, 23\% of American participants, $34 \%$ of Israeli participants of Jewish origin, and $40 \%$ of Israeli students of Palestinian origin resolved the conflict (Table 1).

Three percent of Turkish participants, 10\% of American participants, $16 \%$ of Israeli participants of Jewish origin, and $15 \%$ of Israeli participants of Palestinian origin resolved the conflict in both roles. The order of playing the Israeli and the Palestinian role (which one is played first) did not explain resolving the conflict in the game (that is, winning). A Pearson chi-square test determined that succeeding in PeaceMaker while playing the Israeli role was related to succeeding while playing the Palestinian role $\left(X^{2}(146,1)=4.72, p<.03\right)$. Participants who resolved the conflict playing one role managed to resolve the conflict playing the other role as well.

\section{Explaining Conflict Resolution in the Game}

In the Palestinian role, participants who were more knowledgeable about the conflict $(M=15.33, S D=5.8)$ successfully resolved the conflict while the less knowledgeable $(M=12.87, S D=5.5)$ were not as successful, $t(145)=2.81$, $p<.05$. Likewise, in the Israeli role, participants who were more knowledgeable about the conflict $(M=17.66, S D=5.5)$ were more successful in resolving the conflict compared with participants who were less knowledgeable $(M=14.37$, $S D=5.5), t(145)=2.92, p<.0004$. Regardless of the role played, more knowledge on the situation led to more successful resolution of the conflict compared with less knowledge. In line with our expectations, participants that are direct parties to the conflict (Palestinian and Jewish) resolved the conflict more

TABle 1. Resolving the Israeli-Palestinian Conflict in PeaceMaker

\begin{tabular}{llll}
\hline & Israeli role & Palestinian role & Both roles \\
\hline Israeli-Jews & $32 \%$ & $34 \%$ & $16 \%$ \\
Israeli-Palestinians & $40 \%$ & $40 \%$ & $15 \%$ \\
Turks & $8 \%$ & $30 \%$ & $3 \%$ \\
Americans & $21 \%$ & $23 \%$ & $10 \%$ \\
\hline
\end{tabular}


successfully in all situations compared with the third parties (Turkish and American). This also explains why the Palestinian citizens of Israel have the highest percentage of success in resolving the conflict in both the Palestinian and Israeli roles. Compared with other groups, they are exposed to both narratives and are more knowledgeable about the conflict from both perspectives.

Political attitudes, gender, religious affiliation, average number of weekly hours playing computer games, and average number of weekly hours spent online did not explain successful resolution of the conflict in the game for the Israeli and the Palestinian roles.

Support for two-state solution did not explain resolving the conflict in the game for either the Israeli or Palestinian roles: $55 \%$ of the Israelis of Jewish origin, $40 \%$ of the Americans, $35 \%$ of the Israelis of Palestinian origin, and $32 \%$ of the Turks who played the game supported the two-state solution. Participants opposing a two-state solution resolved the conflict in the game no less than those supporting it.

\section{Action Type in the Game}

We examined whether the four groups differed in the action type they took in the game (Security, Political, or Construction), separately for the Israeli and the Palestinian roles.

The only significant result was obtained for security actions in the Palestinian role. In the Palestinian role, Israeli-Jews took the highest proportion of security actions $(M=33.5, S D=12.3)$ while Israeli-Palestinians took the lowest proportion of security actions $(M=25.46, S D=11.88)$. The Turkish participants $(M=27.7, S D=11.34)$ and the American participants $(M=28.73, S D=11.57)$ took more security actions than Israeli-Palestinians, but less than Israeli-Jews, $F(3$, $146)=2.49, p<.05$.

\section{Game Effects on Perspective Taking on the Conflict}

To examine the game effects on perspective taking, we assessed the pre-game and post-game answers in relation to the Gaza operation and key disputed issues in the conflict (Table 2). For the Gaza operation, we conducted a repeated measures ANOVA with the perspective regarding the rightness of each side in the Gaza operation (before or after playing the game) as a within-subjects factor and with group (Israeli-Jew, Israeli-Palestinian, Turkish, or American) as a betweensubjects factor. The interaction of perspective taking in the Gaza operation and group was significant, $F(3,146)=3.06, p<.032$. American students got closer to thinking that both Israeli and Palestinian sides were equally right regarding the Gaza operation after playing the game $(M=2.98, S D=1.26)$, when they had a more pro-Israeli view before playing the game $(M=3.4, S D=1.18)$. Similarly, Turkish students got closer to thinking that both Israeli and Palestinian sides were equally right regarding the Gaza operation after playing the game

Table 2. Game Effects on Perspective Taking Regarding the Gaza Operation

\begin{tabular}{lcc}
\hline & $\begin{array}{c}\text { Pre-Game } \\
M(S D)\end{array}$ & $\begin{array}{c}\text { Post-Game } \\
M(S D)\end{array}$ \\
\hline Israeli-Jewish & $3.6(1.07)$ & $3.6(1.09)$ \\
Israeli-Palestinian & $1.6(0.07)$ & $1.7(0.68)$ \\
Turkish* & $0.2(1.15)$ & $2.4(1.27)$ \\
American* & $3.4(1.18)$ & $2.9(1.26)$ \\
\hline
\end{tabular}

$($ Note. $* p<.05$. 
$(M=2.38, S D=1.27)$, when they previously had a more pro-Palestinian view $(M=.197, S D=1.15)$. In contrast, Israeli students of Jewish origin did not change their perspective regarding the rightness of each side in the Gaza operation after playing the game $(M=3.6, S D=1.07 ; M=3.6, S D=1.09)$ and thought that Israelis are somewhat right in the Gaza operation. Likewise, Israeli students of Palestinian origin did not change their perspective after playing the game $(M=1.6, S D=0.75 ; M=1.7, S D=0.68)$, and thought that Palestinians are somewhat right in the Gaza operation. In summary, game effects were obtained for American and Turkish students who changed their perspective regarding the rightness of each side in the Gaza operation, but not for Jewish and Palestinian students. Thus, the game was effective in helping third parties develop perspective taking with regards to the Gaza operation, but not for the parties to the conflict.

The fact that the game effects with regard to perspective taking are limited to third parties to the conflict is most likely because Turkish and American participants have less salient and weaker attitudes concerning the conflict, as opposed to Palestinian and Jewish participants who have stronger and more salient attitudes. This finding is in line with research on attitude strength, which suggests that stronger attitudes are more resistant to change and lead to selective cognitive processing (Eagly and Chaiken 1998). Furthermore, when one's attitude is linked to one's "self" concept or value system, the attitude is more resilient to change (Pomerantz, Chaiken, and Tordesillas 1995).

In order to test the game effects on perspective taking concerning other issues in the conflict, we conducted a repeated measures ANOVA regarding the rightness of each side on key conflict issues (before or after playing the game) as a within-subjects factor and with group (Israeli-Jew, Israeli-Palestinian, Turkish, or American) as a between-subjects factor. The interaction of perspective taking regarding key issues in the conflict with group was insignificant, $F(3,146)=.45$, $p<.72$. There are no indications of game effects on perspective taking regarding the rightness of each side concerning key issues in the conflict.

In summary, the game had an effect on the attitudes of third-party students only with regard to the Gaza operation. This may be because of differential familiarity with the issues especially for third parties. The Gaza operation was a recent event at the time of the study, which received extensive media coverage and public debate as opposed to other issues. Participants, due to their age, might be more familiar with this issue and therefore the game had a limited impact on perspective taking.

\section{Game Effects on Knowledge Acquisition about the Conflict}

To examine the game effects on acquiring knowledge about the conflict, we conducted a repeated measures ANOVA with the number of correct answers to factual questions (before or after playing the game) as a within-subjects factor and with group (Israeli-Jew, Israeli-Palestinian, Turkish, or American) as a betweensubjects factor (Table 3). The interaction of the number of correct answers with group was significant, $F(3,146)=13.56, p<.0001$. American students answered more knowledge questions correctly after playing the game $(M=17.6$, $S D=2.17)$ than before playing it $(M=13.5, S D=2.34)$ as well as Turkish students with $(M=9.34, S D=4.29)$ after playing the game and $(M=7.89$, $S D=4.01)$ before playing. Jewish students answered more questions correctly after playing the game $(M=22.12, S D=1.89)$ than before playing it $(M=20.3$, $S D=3.15)$ as well as Palestinian students $(M=21.45, S D=1.85)$ after and $(M=19.4, S D=2.14)$ before playing the game.

Thus, all groups acquired more knowledge significantly on the Israeli-Palestinian conflict as a result of playing the game. American participants acquired more 
TABLE 3. Game Effects on Knowledge Acquisition about the Conflict

\begin{tabular}{llc}
\hline & $\begin{array}{c}\text { Pre-Game } \\
M(S D)\end{array}$ & $\begin{array}{c}\text { Post-Game } \\
M(S D)\end{array}$ \\
\hline Israeli-Jewish* & $20.3(3.15)$ & $22.12(1.89)$ \\
Israeli-Palestinian* & $19.4(2.14)$ & $21.45(1.85)$ \\
Turkish* & $7.9(4.01)$ & $9.34(4.29)$ \\
American* & $13.5(2.34)$ & $17.6(2.37)$ \\
\hline
\end{tabular}

$($ Note. $* p<.0001$.

knowledge on the conflict compared with Turkish, Jewish, and Palestinian participants, but the latter two had prior high levels of knowledge on the Israeli-Palestinian situation and so did not have much more to gain. Although the game increased the level of knowledge for all groups in a statistically significant way, the effect was again stronger for the third parties to the conflict.

Overall, the game was an effective teaching tool concerning the Israeli-Palestinian conflict for both parties to the conflict and for third parties. Even for the Jewish and Palestinian participants that were already knowledgeable about the conflict, it had a positive effect. Despite its limited effect on perspective taking, increased knowledge acquisition for all groups is an important outcome especially considering our earlier finding which suggests that the level of knowledge is highly correlated with the ability to successfully resolve the conflict. PeaceMaker is, therefore, a teaching tool that is useful for introducing conflict assessment and resolution skills.

\section{Conclusion}

This study aims to assess the impact of computer-based simulations in conflict resolution teaching and whether these effects change from one context to another. By using the PeaceMaker game, which is a structured simulation of the Israeli-Palestinian conflict, using a cross-cultural experimental design, we assessed whether participants can increase their knowledge about the conflict and develop perspective taking, and whether these effects changed with being direct parties to the conflict as opposed to third parties. The results are promising albeit requiring further assessment. First, in all groups, the game significantly improved participants' level of knowledge about the conflict. All four groups became more knowledgeable about the conflict after playing the game. Second, the game changed the attitude of third-party participants concerning the Gaza operation and contributed to perspective taking. It led Turkish and American participants to adopt a more impartial attitude compared with their pre-game attitudes. Although this effect is limited, the result is sufficiently encouraging for us to conduct further studies.

This study is a first step in analyzing the effects of computer-based simulations in conflict resolution and further studies are necessary to understand under what conditions technology can be used as an effective conflict-resolution intervention. Additional studies are needed especially to understand how simulations and games can effectively contribute to perspective taking, building empathy between the parties to the conflict. It is particularly necessary to see whether limited effects are specific to computer-based simulations or pertain to all types of simulations. Further systematic studies are required to compare the effects of traditional simulations with more structured, computer-based simulations like PeaceMaker. Our findings encourage more research on computer-based simulations and perspective taking specifically in the case of third-party actors. Additional research should look into the effects of games like PeaceMaker on third 
parties and explore whether such technology-based teaching tools can be used to train third-party mediators effectively. Lastly, future studies can also examine the effect of simulations in generating perspective taking within the context of a particular conflict, in the same way as PeaceMaker, as opposed to using computer-based simulations to deal with multiple conflicts.

Finally, our study has implications for the scholarship on active learning and teaching assessment. Considering the mixed results obtained so far with regard to the effectiveness of simulations, our findings favor computerized game simulations as an effective teaching method. They not only contribute to the improvement of knowledge in that specific conflict, but also improved perspective taking albeit in a limited manner.

Another implication for the active learning and teaching scholarship is that the variation in the results obtained from different cultural contexts indicates the importance of context for learning from simulations. In addition to the different learning outcomes we observed in different cultural contexts, the PeaceMaker game has clearly shown that learning effects for direct participants to the conflict are different from those for participants from third parties to the conflict. The effect of context on learning from simulations should perhaps encourage scholars of active teaching and learning to direct their attention to explore the contingencies of effectiveness for simulations rather than adopting dichotomous research questions that ask whether simulations are useful or not useful.

\section{References}

Alexander, Nadja, and Michelle LeBaron. (2009) Death of the Role Play. In Second Generation Negotiation Teaching, Vol. 1, edited by Christopher Honeyman, James Coben, and Giuseppe De Palo. St. Paul, MN: DRI Press.

Asal, Victor. (2005) Playing Games With International Relations. International Studies Perspectives 6: $359-373$.

Asal, Victor, and Jayson Kratoville. (2013) Constructing International Relations Simulations: Examining the Pedagogy of IR Simulations through a Constructivist Learning Theory Lens. Journal of Political Science Education 9: 132-143.

Baylouny, Anne Marie. (2009) Seeing Other Sides: Nongame Simulations and Alternative Perspectives of Middle East Conflict. Journal of Political Science Education 5: 214-232.

Bhappu, Anita, Noam Ebner, Sanda Kaufman, and Nancy Welsh. (2009) The Strategic Use of Online Communication Technology to Facilitate Relational Development in Executive Training Courses on Negotiation. In Second Generation Negotiation Teaching, Vol. 1, edited by Christopher Honeyman, James Coben, and Giuseppe DePalo. St. Paul, MN: DRI Press.

Boin, Arjen, Celesta Kofman-Bos, and Werner Overdij. (2004) Crisis Simulations: Exploring Tomorrow's Vulnerabilities and Threats. Simulation and Gaming 35 (3): 378-393.

Brown, Scott, Mark Boyer, Hayley Mayalll, Paula Johnson, Lin Meng, Michael Butler, Kimberly Weir, Nathalie Florea, Magnolia Hernandez, and Sally Reis. (2003) The GlobalEd Project: Gender Differences in a Problem-Based Learning Environment of International Negotiations. Instructional Science 31: 255-276.

Burak, Asi, Eric Keylor, and Tim Sweeney. (2005) PeaceMaker: A Video Game to Teach Peace. Intelligent Technologies for Interactive Entertainment. Lecture Notes in Computer Science 3814: 307-310.

Chalamish, Michal, and Sarit Kraus. (2012) AutoMed: An Automated Mediator for Multi-Issue Bilateral Negotiations. Autonomous Agents and Multi-Agent Systems 24 (3): 536-564.

Druckman, Daniel. (2011) Negotiation and Mediation. In Cambridge Handbook of Experimental Political Science, edited by James N. Druckman, Donald P. Green, James H. Kuklinski, and Arthur Lupia. New York: Cambridge University Press.

Druckman, Daniel, V. Robinson. (1998) From Research to Application: Utilizing Research Findings in Training Programs. International Negotiation $3: 7-38$.

Druckman, Daniel, and Noam Ebner. (2008) Onstage or Behind the Scenes? Relative Learning Benefits of Simulation Role Play and Design. Simulation and Gaming 39 (4): 465-497.

Druckman, Daniel, Jamie Druckman, and Tatsushi Arai. (2004) E-Mediation: Evaluating the Impacts of an Electronic Mediator on Negotiating Behavior. Group Decision and Negotiation 13: 481-511. 
Druckman, Daniel, Alexander Dannenman, Michael Filzmoser, Johannes Gettinger, Sabine Koeszegi, Ronny Mitterhofer, Reiser, Marieke Schoop, Rudolf Vetschera and Per van der Wijst. (2011): e-nego-motion: Integration of Behavioral and Decision Support in e-negotiations, in Proceedings of the 24th Annual International Association for Conflict Management (IACM) in Istanbul, Turkey.

Eagly, Alice, and Shelly Chaiken. (1998) Attitude Structure and Function. In The Handbook of Social Psychology, 4th edn, Vol. 1, edited by Daniel T. Gilbert, Susan T. Fiske and Gardner Lindzey. New York: McGraw-Hill.

Ebner, NoAm. (2008) Online Dispute Resolution: Applications for e-HRM. In Encyclopedia of Human Resources Information Systems: Challenges in e-HRM, edited by T. Torres-Coronas and M. Arias-Oliva. Hershey, PA: Idea Group Reference Publishing.

Ebner, Noam, and Yael Efron. (2005) Using Tomorrow's Headlines for Today's Training: Creating Pseudo-Reality in Conflict Resolution Simulation Games. Negotiation Journal. 21 (3): 377-393.

Galin, Amira, Miron Gross, and Gavriel Gosalker. (2007) E-negotiation versus Face-to-Face Negotiation What Has Changed-If Anything? Computers in Human Behavior 23: 787-797.

Gehlbach, Hunter, Scott Brown, Andri Ioannou, Mark Boyer, Nathalie Hudson, Anat Niv-Solomon, Donalyn Maneggia, and Laura Janik. (2008) Increasing Interest in Social Studies: Social Perspective Taking and Self-Efficacy in Stimulating Simulations. Contemporary Educational Psychology, 33 (4): 894-914.

Gonzalez, Cleotilde, Lelyn D. Saner, and Laurie Z. Eisenberg. (2012) Learning to Stand in the Other's Shoes: A Computer Video Game Experience of the Israeli-Palestinian Conflict. Social Science Computer Review 31 (2): 236-243.

Hannafin, Michaael, and Minchi Kim. (2003) In Search of a Future: A Critical Analysis of Research on Web Based Teaching and Learning. Instructional Science 31: 347-351.

Hermann, Charles. (1969) Crisis in Foreign Policy: A Simulation Analysis. Indianapolis: Bobbs Merrill.

Honeyman, Chris, Jim Coben, and Giuseppe De Palo. (2010) Venturing Beyond the Classroom, Vol. 2. St. Paul, MN: DRI Press.

Kersten, Gregory E., Sabine Koszegi, and Rudolf Vetschera. (2003) The Effects of Culture in Computer Mediated Negotiations: Experiments in 10 Countries. Journal of Information Technology Theory Applied 5 (21): 1-28.

Krain, Matthew. (2010) The Effects of Different Types of Case Learning on Student Engagement. International Studies Perspectives 11 (3): 291-308.

Krain, Matthew, and Jeffrey Lantis. (2006) Building Knowledge? Evaluating the Effectiveness of the Global Problems Summit Simulation. International Studies Perspectives 7: 395-407.

Krain, Matthew, and Christina Shadle. (2006) Starving for Knowledge: An Active Learning Approach to Teaching About World Hunger. International Studies Perspectives 7: 51-66.

LANTIS, JefFrey S. (1998) Simulations and Experiential Learning in the International Relations Classroom. International Negotiation: A Journal of Theory and Practice 3 (1): 39-57.

Lantis, Jeffrey, Kent Kille, and Matthew Krain. (2010) The State of the Active Teaching and Learning Literature. In The International Studies Encyclopedia, Vol. 10, edited by Robert A. Denemark. Malden, MA: Wiley-Blackwell.

Lawless, Kimberley, and Scott Brown. (2003) Introduction: From Digital Road to Educational Expressway: Innovations in Web-Based Pedagogy. Instructional Science 31: 227-230.

Lay, J. Celeste, and Kathleen J. Smarick. (2006) Simulating a Senate Office: The Impact on Student Knowledge and Attitudes. Journal of Political Science Education 2 (2): 131-146.

Lewicki, Roy J. (2000) Teaching Negotiation and Dispute Resolution in Colleges of Business: The State of the Practice. In Teaching Negotiation: Ideas and Innovations, edited by Michael Wheeler. Cambridge: PON Books.

Lin, Raz, Yehoshua Gev, and Sarit Kraus. (2011) Bridging the Gap: Face-to-Face Negotiations With Automated Mediator. IEEE Intelligent Systems 26 (6): 40-47.

Loewenstein, Jeffrey, and Leigh Thompson. (2000). The Challenge of Learning. Negotiation Journal, October: 399-408.

Matz, David, and Noam Ebner. (2010) Using Role Play in Online Negotiation Teaching. In Venturing Beyond the Classroom, Vol. 2, edited by Christopher Honeyman, James Coben, and Giuseppe De Palo. St. Paul, MN: DRI Press.

Movius, Hal. (2008) The Effectiveness of Negotiation Training. Negotiation Journal, October: 509-531.

Nadler, Janice, Leigh Thompson, and Leaf VAN Boven. (2003) Learning Negotiation Skills: Four Models of Knowledge Creation and Transfer. Management Science 49 (4): 529-540.

Pomerantz, Eva, Shelly Chaiken, and Rosalind Tordesillas. (1995) Attitude Strength and Resistance Processes. Journal of Personality and Social Psychology 69 (3): 408-419. 
Powner, Leanne, and Michelle Allendoerfer. (2008) Evaluating Hypotheses About Active Learning. International Studies Perspectives 9: 75-89.

Raymond, Chad. (2010) Do Role-Playing Simulations Generate Measurable and Meaningful Outcomes? A Simulation's Effect on Exam Scores and Teaching Evaluations. International Studies Perspectives 11: 51-60.

Torney-Purta, Judith. (1998) Evaluating Programs Designed to Teach International Content and Negotiation Skills. International Negotiation 3 (1): 77-97.

Volkema, Roger. (2007) Negotiating for Money: Adding a Dose of Reality to Classroom Negotiations. Negotiation Journal, October: 473-485.

Wilkenfeld, Jonathan, Kathleen Young, David Queen, and Victor Assal. (2005) Mediating International Crises. Oxford: Routledge.

Williams, Victoria C. (2006) Assuming Identities, Enhancing Understanding: Applying Active Learning Principles to Research Projects. Journal of Political Science Education 2: 171-186. 